\title{
Cash Transfer with Turkish Characteristics: Two Local Examples
}

\begin{abstract}
Having discussed the emergence of cash transfer (CT) as an instrument not only for economic assistance but potentially for inclusion in a market-centered society, and the policy environment of contemporary Turkey, we now bring these together through examination of two case studies of CT programs designed and implemented at the local level. By proceeding in this way, we are explicitly eschewing any claim to providing a universal treatment of social policy, or even of CT programs, in contemporary Turkey. Rather, we consider these cases with a view to highlighting the elements that seem most closely tied to particular outcomes, and then to generalizing these in the form of hypotheses applicable beyond Turkey.
\end{abstract}

Keywords Turkey $\bullet$ Local government $\bullet$ Social cash transfer • Outcomes • Social citizenship

As detailed in Chap. 3, the use of various types of CT instruments has become widespread in twenty-first-century Turkey. These include categorical programs aimed at widows, students, disabled persons, etc. There has also been an increase in conditional CT programs, such as those launched under the Word Bank's Social Risk Mitigation Program (SRMP) in 2002 (World Bank 2008). The impact of such programs remains an open question. In the introduction to a World Bank sponsored study of the use of cash for food assistance, Alderman et al. (2018:2) conclude that: “... cash 
can, under the right circumstances, provide choice, empower recipients, and generate local economic multipliers." But what are the right circumstances? And how, if it does occur, does such choice and empowerment translate into the type of inclusion conducive to the "basic equality of membership" at the core of Marshallian social citizenship?

It is to begin answering these questions that we turn to two case studies of unconditional CT designed and implemented at the local level. Our first case is a program led by the district Social Assistance and Solidarity Foundation (SASF), while the second was put in place by a district municipality. In both cases, CT programs replaced existing schemes of in-kind food distribution. An important reason for our choice of these cases is that, unlike the World Bank's Social Risk Mitigation Program, they are the result of Turkish initiatives at the local level, and emerge from local practice. Because they share the national institutional context detailed in Chap. 3, comparison between them can control for the effect of national-level institutions and laws, and notoriously problematic factors such as "national culture," allowing us to focus on the differences that matter: elements of program design and concrete implementation that determine outcomes in practice. In order to preserve the anonymity of our interview partners, we do not identify the specific districts taken as examples, but rather give a general description of their location and situation. As the first is in a predominantly rural zone and the second in a major urban area, we will designate them as " $R$ " and "U", respectively.

\section{The Case of a Rural District}

The district of $\mathrm{R}$ is largely rural: in February 2019 it had a population of approximately 61,000, of which one-third lived in villages and two-thirds in the capital city. Politically, the district and the province of which it is a part have been dominated since 2009 by the CHP, the center-left secular party in opposition at the national level. Our principal finding in this case was that the small scale and limited resources of authorities had several negative consequences. The number and training of social assistance workers was inadequate for evaluation of applicants' needs; they produced data whose accuracy was difficult to assess. The district SASF depended for implementation on a private-sector contractor. This, in turn allowed the service provider to limit participating merchants to those already in its network, leading to higher-priced shops being chosen and limiting the 
value of cash transfer. Authorities' attempts to monitor transactions, finally, were an administrative burden on participating shops. Failure to comply with monitoring requirements led to reimbursement to shops being withheld to the detriment of the program's sustainability.

\subsection{An Instrument for Individual Empowerment?}

In 2015, the district's SASF replaced the distribution of food parcels to the lowest income families with prepaid smart cards that allow them to purchase a defined set of products on the model of the "gift cards" sold by certain companies. The technical specifications of the card were modeled on those of the Electronic Platform for Public Procurement [Elektronik Kamu Alımı Platformu, EKAP] as well as electronic card suppliers such as Multinet and Sodexo. Since it did not have the technical resources to design such a tool itself, the SASF issued a call for tenders including both the physical aspects of the instrument (smart cards and the associated computer management system) and its commercial aspects (network of shops where the card would be accepted). In the end, only one company responded, probably because the scale of the district limited profits for large companies. The local foundation signed a contract with Multinet, which was replaced by Metropol in 2016 following suspicion that the former had links to the movement of Imam Fethullah Gülen, who was accused by the authorities of orchestrating the failed coup d'état in the summer of $2016 .^{1}$

The use of the card, as originally conceived, was limited to the purchase of food during Ramadan and the Feast of Sacrifice (kurban bayrami). In 2018, 750 families were able to benefit from these cards, which had a registration number but did not bear the name or photo of the user. The card was reloaded in increments of 200 Turkish Liras (TL) ${ }^{2}$ and could be used in the local branches of five national supermarket chains, selected by Multinet and then Metropol as part of their management contract. Certain items such as alcohol, tobacco products, jewelry, furniture and cleaning products could not be purchased with this card.

\footnotetext{
${ }^{1}$ Interview: 2019. For background on the failed coup, see: https://www.hurriyet.com. $\mathrm{tr} /$ gundem/dakika-dakika-darbe-girisimi-15-16-temmuz-2016-40149409, consulted 10 April 2020.

${ }^{2}$ See the discussion of currency conversion in Chap. 1 .
} 
The payment card program was financed from the national budget of the Solidarity Fund. Prior to launching the card program the local SASF received a monthly payment (periodik yardim) of TL 123,500 from the General Directorate of Social Assistance to ensure the payment of the salaries of its seven employees. Additional shares of aid were paid to the SASF on the occasion of Ramadan and the Feast of Sacrifice. In the past, these had financed the distribution of food packages; they became the source of funds distributed to the families through the prepaid cards.

From the point of view of the local foundation, the switch from in-kind donations to the social card program was justified in terms of the quality of the products available and the freedom of choice left to the beneficiaries. The foundation director explained:

\begin{abstract}
Before the food cards, we used to distribute food parcels during the holiday season. Although there are quality specifications in the food packaging process, the food was of very poor quality. We drank the tea that was in the food parcel, it tasted horrible. We told the companies that wanted to participate in the tender that they had to at least provide good quality tea. But another company won the tender, and the quality of the tea was poor.

One day I went to an old lady's house. She was very poor. She told me, "I looked out my window all winter long. There was a street vendor selling oranges and apples. But I can't even buy one."
\end{abstract}

As with all actions financed by the Solidarity Fund, whether in-kind or cash, information on low-income people is provided by Turkey's integrated Social Assistance Information System (ISAIS). Home visits to collect and maintain this information are at the heart of this system. These are carried out by inspectors employed by local foundations. According to official documentation, the visits are carried out at least once a year to allow for a consistent and objective assessment of needs (Ministry of Family and Social Policy and World Bank 2017: 23).

Reinforcing its market-enhancing perspective, the monetization of social assistance is closely integrated with the local economy. While the food parcels at the heart of the old system did not come from the local market, beneficiaries of the social card spend the resulting income in local shops, providing an indirect subsidy to the participating businesses. The

\footnotetext{
${ }^{3}$ Interview, 2019.
} 
local authorities can, in principle, exert an important influence on local economic life by selecting the shops entitled to participate in this program.

\subsection{Problems of Implementation}

In practice, the procedures observed deviated significantly from the ideals of market citizenship. From the outset, the fact that the SASF had to call on external suppliers resulted in a delegation of the choice of participating businesses to the Multinet and then Metropol companies. In their role as service providers, they were the ones who selected the participating businesses from among their business partners. The selected shops were all branches of large national supermarket chains. This led directly to several problems.

From the perspective of the SASF, administration proved difficult. In order to monitor users and purchases, the Foundation asked participating businesses for an invoice for each purchase and a photocopy of the identity cards of the person making the purchase. If these were not provided, it refused to pay the merchant. The participating supermarkets proved unable or unwilling to collect the information required by the card providers who, in turn, were unable to provide it to the Foundation. This resulted in refusals to pay and reduced profitability for the suppliers. Finally, the Foundation itself did not have the human resources to carry out its part of the control procedures. Purchases related to each card had to be verified on a monthly basis. The Foundation's staff of seven people, two of whom were dedicated to the verification of card purchases, was insufficient for this task, which finally could not be carried out. This led to a weakening of the relation between system designers and service providers, to the detriment of the program's sustainability. ${ }^{4}$

A distinct problem, from the perspective of users, was limited choice. The restriction of the use of the card to the five supermarkets selected by the companies providing the program was also widely criticized by program users. "We cannot go to Al01 or BİM [national discount stores]! There is a restriction of shops for purchase. We buy the same food with more expensive prices!" ${ }^{5}$ Under these circumstances, some expressed a preference for the old system:

\footnotetext{
${ }^{4}$ Interview, 2019.

${ }^{5}$ Interview, 2019.
} 
There used to be food parcels. There was a lot of food in that parcel. Oil, dish soap, flour, dry food in large quantities! We couldn't buy the same amount with the card. It was better before. But, thank God for this anyway. (Fakat buna daşükür)! ${ }^{6}$

A third set of problems were linked to the system of home inspection that was intended to verify the eligibility of users. Although the data found in the Integrated Social Assistance System (ISAIS) were used, the behavior of the social assistance inspectors showed considerable discretionary power. To some extent, this was built into the procedures; some items on the assessment forms were left to the inspectors' judgment: "did you find a negative attitude towards children in the family?"; "did you find a pattern of negative habits in the family?". In addition, inspectors sometimes chose not to apply the official questionnaire directly. The lengthy survey provided for in the procedure ( 49 questions) was usually completed by the inspectors themselves without the questions being asked directly to the respondents. ${ }^{7}$ Inspectors, moreover, had no standardized procedures or protocols, nor any formal training on the technical or ethical aspects of assessing poverty and need. In practice, procedures were generated by the inspectors themselves and informally passed on within the inspection teams, with the more experienced inspectors teaching newcomers what they considered relevant. There was no guarantee that assessment would be consistent from one inspector to another. ${ }^{8}$ Moreover, our interviews with card recipients suggested that inspections were carried out only once, to determine initial eligibility, and were not repeated afterward, contrary to official procedure. ${ }^{9}$ Overall, the picture that emerged from the household visits is one of subjectivity rather than of the technical uniformity intended when the instrument was adopted. These visits were intended to provide additional information to the ISAIS. In the case of $\mathrm{R}$, however, the impression of coherence and harmonization evoked by this system was misleading.

From the point of view of the director of the local foundation, the program was not considered a success. ${ }^{10}$ In his view, the poorly educated beneficiaries, especially the older ones and those with disabilities, were not

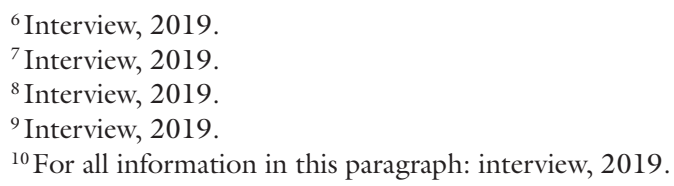


able to use the cards properly: many forgot the password associated with their card, while others did not understand that the card had a limited amount of money on it and tried to make purchases beyond the credit they had been given.

The gap between principle and reality was also evident from the point of view of program beneficiaries, but the reasons they gave proved to be quite different from that of the local authorities. ${ }^{11}$ The use of the cards themselves - storage of access codes, etc.- - did not seem to be a problem. Quite to the contrary these same people were already using the national PTT card. In their view, having money gave them more freedom in their choice of consumption, although the Foundation authorities did not anticipate the resulting choices. One disabled respondent thus managed to divert the use of the card to purchase medicines, which are normally excluded from accessible products, by the expedient of first purchasing food which he exchanged for cash with a neighbor, and then using the cash to purchase medication. ${ }^{12}$

Beyond such benign creativity, however, was a more general feeling of diffidence about the program and the way it was carried out. Did aid really go to the neediest? Some persons interviewed expressed a preference for informal employment, since the resulting unreported income did not enter into the determination of their eligibility for social assistance. Others recounted an anecdote-obviously unverifiable, but interesting for the point of view it typifies - that in the past year "party members were making lists, and then some people had their aid cut" leaving them with the feeling that any talk about aid might result in losing it. ${ }^{13}$ The arbitrary nature of inspections, mentioned earlier, also led to perceptions of unequal treatment, opening the way to conflict and divisions among recipients.

The foundation director suggested that within the board itself civil society members were chosen by the mayor according to political affiliation. ${ }^{14}$ Under such conditions, assistance might be subverted to serve elite interests rather than furthering individual equality. It is important to emphasize that no clear evidence either of political or of personal preferential treatment was offered. Even so, the suspicion, whether based in reality or rumor, that obtaining — and losing — assistance was largely arbitrary or could be influenced by political considerations, or that concealing

\footnotetext{
${ }^{11}$ Interview, 2019.

${ }^{12}$ Interview, 2019.

${ }^{13}$ Interview, 2019.

${ }^{14}$ Interview, 2019.
} 
income was prudent, speaks of a program that contributed little either to empowerment or inclusion.

The Foundation's director, inspectors, and card users, each for distinct reason of their own, found the program to be dysfunctional. Acknowledging this result, the SASF decided in 2019 to end this experiment with an autonomous instrument and to adopt the PTT card as a tool for distributing aid. This choice had no impact on the sums distributed; recipients now have access to local aid on the PTT card, which most of them already used to access other State aid. The result saves resources for the Foundation, which no longer has to ensure technical monitoring, but also represented the end of any attempt to monitor the consumption behavior of the beneficiaries. The switch to the PTT card also ended the monopoly of the shops preselected by the supplier, which presumably allowed recipients to obtain food at better prices. The issues noted with respect to inspections determining who should or should not receive assistance, however, were not addressed and remain problematic.

\section{The Case of an Urban District}

In our second case, the urban district of $U$, the instigator of the program was the district municipality. Located in an urban area, the district had a population of 427,800 in 2018 , having doubled in 10 years. This change in size compared to $\mathrm{R}$ is reflected in the means available. Where, in the case of R, only the district SASF, mobilizing a budget from the National Solidarity Fund, could envisage the implementation of a local social welfare policy, the U District Municipality could use its own budget, supplemented by private donations. The result was a system that did not need to call on an outside contractor; the district municipality was both financer and implementor. The resulting market-enhancing instrument, we find, resulted in a greater degree of integration into the local market. At the same time, however, it increased the political dependence of recipients on the municipality and the governing party; market inclusion in this case did not fully translate into individual autonomy.

\subsection{An Innovative Local Instrument}

A distinctive element of U's strategy is the early use of innovative social policy instruments as an additional means of inclusion for the poorest part of the population. The policy instrument was created in 2010 -preceding 
the World Bank's SRMP by two years. As in the case of R, a debit card was used as the program's vehicle, this time inspired by the limited-sum debit cards introduced by some banks for the younger segments of their clientele. The result was a permanent payment card that is regularly recharged by the municipality and used for purchases of food, clothing, school supplies, and some medical items such as wheelchairs. The card is given only to women on the basis of family income. In 2018, 5,500 families received the social assistance card for food. ${ }^{15}$ The card is personal and carries a photo of the user. The card is topped up in installments of 200 Turkish liras (TL) with a supplement of TL 5 for each child between 6 and 18 years of age. If one of the parents is deceased, a supplement of TL 5 is added per child. The frequency of recharging the card depends on the per capita family income, so that poorer families receive more frequent assistance (cards are recharged every month instead of every three months or more). Those whose cards are recharged monthly also receive assistance for the purchase of clothing to the amount of TL 110 for each family member. As of 2018, 19,708 persons lived in households eligible for the card. ${ }^{16}$ Users can check the amount available on their card at any time. There is no time limit for purchases; the credit is valid until it is exhausted. Criteria other than income can also be taken into consideration. People with disabilities can receive a credit for the purchase of necessary medical equipment; families who have lost their homes in a fire can receive an additional credit for the purchase of building materials.

As in the case of $\mathrm{R}$, the payment card issued in $\mathrm{U}$ can only be used in shops selected by the municipality and equipped with a suitable card reader. Sixteen businesses in the district are accredited to accept the card for food and as many for clothing payments. ${ }^{17}$ Participating businesses must hold a municipal license, have a space of at least 150 square meters, a bar code reader, and must not sell illegal items or food after its expiry date. Owners must have a clean criminal record and not employ any undeclared workers. The control effort is thus even more evident than in the instrument set up in $\mathrm{R}$, since in this case it concerns local shops designated by the municipality, and not national supermarkets chosen by a private sector service provider.

${ }^{15}$ District municipality of $\mathrm{U}$, annual report of activities, 2018.

${ }^{16}$ It is illustrative of the greater administrative capacity of $U$ that, unlike in $R$, authorities had an accurate count of individuals—not just households.

${ }^{17}$ District municipality of $\mathrm{U}$, annual report of activities, 2018. 
One point in common with $\mathrm{R}$ is that the origin of the payment card was linked by its creators to local needs and in particular to certain proven dysfunctions of traditional systems of in-kind aid. An illustrative anecdote along these lines was told to us by the former deputy mayor of the district: during the distribution of Ramadan aid by the municipality in 2009 , the dry chickpeas distributed in the parcels systematically ended up in the rubbish bins. After carrying out a survey in the neighborhoods, our interlocutor learned that the chickpeas were thrown away because of the cost of cooking them, considered too high by the beneficiaries. A female inhabitant reportedly told him that to cook these pulses she had to spend more than half of a gas bottle. Transformed into legitimizing narratives, these anecdotes take up the elements of choice that we saw in the first case. Here, as in R, we find support for the conclusions of Buğra and Keyder (2003), according to which aid in-kind generates considerable costs for public administrations, is ineffective for both producers and consumers, and is stigmatizing to those who receive it.

The consequences of the difference in resources from one local authority to another was evident in the management of the instruments. Whereas the District Foundation in $\mathrm{R}$ remained dependent on external for-profit service providers, the municipality of $U$ internalized management and control activities. Information about users is collected by municipal employees who make home visits during which they fill out a 250 -item questionnaire, 196 of which relate to the economic level of the household. According to an official of the municipal social services, these answers are entered into an online system created by the district municipality's officers, enabling them to follow-up each case in real time. This local mastery of the computer tool emerges as one of the most striking differences between our two cases.

Contrary to the result observed in $\mathrm{R}$, the popular success of the payment card in $\mathrm{U}$ is not in doubt. While the residents of $\mathrm{R}$ were apprehensive about the inspectors' visit, fearing that these would take away the aid they were already receiving, we observed women in U queuing, sometimes for hours, to ask for home visits, which they hoped would open up the rights to the payment card. ${ }^{18}$ This difference is explained by the fact that the visits in question were not made by representatives of the municipality but by (systematically women) AKP activists. In principle, these initial visits conducted by party activists had no official value; they had to be

${ }^{18}$ Recurring participant observation, 2014. 
completed and validated by municipal officials. In the minds of the inhabitants, however, the two institutions were seen as one and the same.

This perceived role of a political party in selecting beneficiaries of a public program generates obvious questions of partisanship. Has social policy become no more than a means of rewarding political support? The explanation of the president of a neighborhood party organization could be interpreted in this sense when he says, "I know the problems in this neighborhood from A to Z. I try to prevent those who are not truly needy from obtaining the card." Truly needy, or truly loyal, a cynical observer might ask? ${ }^{19}$ Residents who supported the opposition CHP believed that they faced discrimination in obtaining the payment card. We did observe, however, that supporters of other opposition parties were among the card recipients. As one woman party worker told us: "Women tell me that they will vote for AKP now, even though their husbands do not. What do men know? They are never home!" There is no doubt that we are very far, here, from a world of neutral disinterested civil servants and universal rights. Political calculations are clearly made and openly discussed. In terms of objective output, however, this distinction may be less significant than one might initially imagine. The dynamic described by Piattoni (2001) in which a dominant party finds it in its long-term electoral interest to provide public services to the population at large, which we see at work here, brings results surprisingly similar to what a rights-based dynamic might generate.

\subsection{From Social Penetration to Local Knowledge}

The omnipresence of local workers and activists of the ruling party, the $\mathrm{AKP}$, in low-income neighborhoods of the district was a constant of life in $\mathrm{U}$ after 2012. In addition to organizing political meetings and activities, they could be found at purely social gatherings such as weddings and funerals. As they were themselves residents of the neighborhoods where they worked, the party activists were easily accepted in all these circles. This strategy of local anchoring is not new in Turkey. White (2002) has shown that Islamist parties have, at least since the 1990s, perfected a

${ }^{19}$ Interview, 2012. 
model of political action deeply rooted in everyday life. Like its predecessor, the Prosperity Party [Refah Partisi], the AKP communicates and personalizes its messages to local residents.

Significantly, many of the party workers active in low-income neighborhoods of $U$ were also volunteers for religiously based foundations closely allied with the AKP at both the local and the national levels. This link, which is a frequently observed element of contemporary Turkish reality, has been criticized as reintroducing a "logic of charity" (Buğra 2015), into what should be a system based on rights of citizenship. While it is entirely possible that religious duty was easily allied with political expediency for many party workers, it remains that this dual role seems to have facilitated the construction of relations of trust between them and the poorest residents. Religious foundations, in the words of the local representative of one of these, "can act as a bridge between the people and the state" especially for those, such as internally displaced persons from eastern Anatolia, whose personal experience has led them to mistrust the government. ${ }^{20}$ In the context of a means-tested program, this additional element of social penetration was also a source of information allowing aid to be targeted and its effects to be assessed.

This social anchoring of the party and its allies facilitated its effort to integrate inhabitants into the market while providing an essential relay for the municipal authorities who were thus informed of local conditions. The neighborhood president cited above who knew his neighbors' problems "from A to Z" was not an isolated case. Information available to public authorities was not limited to official databases. Our observation left little doubt that the amount and quality of relevant information available to authorities in $\mathrm{U}$ was significantly superior to what we saw in $\mathrm{R}$. How this information was used was a matter of some controversy. As noted above, residents who identified with opposition parties generally believed, rightly or wrongly, that AKP supporters were systematically given preference. The payment card system in $U$ is not an ideal rights-based policy; even so, it is arguably more effective at promoting market integration than the system of in-kind distribution it replaced.

${ }^{20}$ Interview, 2014. 


\section{Did Cash Transfer Promote Market Citizenship?}

The first conclusion to be drawn from the divergent experience and outcome of the two programs described above is that we must be wary of sweeping generalization, whether it is about CT as an instrument, or Turkey as a context. While both cases present undeniable "Turkish characteristics," shared elements interact with local differences to provide different official outcomes and subjective experiences. Both commonalities and variation help us to address the central question that emerged from the discussion in our first chapters: do the programs we observe use marketenhancing instruments to contribute to social citizenship? The simple answer is that both remain far from a perfect realization of this ideal; cash transfer on its own is not a guarantee of social citizenship, even in the context of a market society. Differences between the two cases, however, are significant.

The objective difference in conditions between $\mathrm{R}$ and $\mathrm{U}$ can be attributed, at least in part, to the evident difference in scale; the two districts differed by an order of magnitude in population. The result of this difference was evident in terms of system design and sustainability. The system in R was marked by the difference of interest between public authority and the private-sector service provider. Because it controlled the digital information system required to operate CT, Multinet imposed the choice of merchants already in its network without consideration of the needs of low-income people. This explains the diminished value of assistance compared to the old system of in-kind distribution. The outcome in $U$ was more coherent, since the municipality retained control of the digital information system and was able to impose its own choice of participating merchants. This difference underscores the fact that the technical requirements of digital CT systems are beyond the capacity of small units that were able to carry out in-kind distribution.

Even if resources are available, how they are used is a matter of policy choice. Other things being equal, the shift to cash transfer tends to shift authority and decision-making capacity toward larger and more capable units, either public or private. The shift to a market-enhancing instrument, thus, is the very opposite of "policy on the cheap," or a "retreat of the state." Before we leap to the conclusion that bigger is necessarily better, however, the contribution of local knowledge to the success of cash transfer in $U$ suggests that there may be a limit to optimal scale. This is a point to which we will return in the following chapters, when we look at the much larger nation-wide program aimed at refugees. 
From the perspective of the recipients of assistance, and this is what really matters, our two cases strongly suggests that how CT programs are viewed depends on very practical matters. If, as in $\mathrm{R}$, the move to cash translates to the purchase of less food than was in the parcels distributed before, it is unsurprising that the program was disliked. If, as in $U$, the practical consequences are positive, acceptance is more easily secured.

Beyond this, we have noted that among the critical questions to be asked of any social support program were: is assistance a right or privilege? If a right, then for whom? In both of our cases, the answer, at least in principle, was that assistance was a right for the poorest families; access was determined by need. Assessing actual need, however, is not a straightforward task; it requires both information and judgment. The experience of $\mathrm{R}$ shows what happens when this assessment is left to the discretion of untrained inspectors. The atmosphere was marked by suspicion and fear of losing benefits. Because undeclared income from informal work could be concealed, residents expressed a reluctance to take on formal employment. In $\mathrm{U}$, authorities were better informed, both officially and informally through the networks of volunteers for the incumbent party. The problem, as it was perceived there, was a suspicion that people likely to support the governing party would receive preference.

In neither case did CT meet the standards either of a fully rights-based approach to social assistance or to unfettered access to the market. In the case of $\mathrm{U}$, the establishment of CT contributed to increasing dependence on the party that dominates the municipality. It does not follow, however, that the shift from in-kind assistance to CT made no difference at all. While it would be absurd to suggest that the sums transferred were sufficient to bring about perfect equality, or even to lift recipients out of poverty, observation suggests that small but significant steps in the direction of inclusion did result. In the context of a market society, their "tradebased entitlement," to return to Sen's (1981) vocabulary, was undeniably increased. It is important, moreover, to remember that the alternative to this limited move toward market citizenship is not an ideal world of universal rights, but a reality of poverty and personal dependence on landlords and brokers. If even a small additional monthly income makes women less dependent on family or households less likely to fall into chronic debt to shopkeepers, the gain in autonomy is real. If CT, for all the limits imposed on its use, is less stigmatizing and provides more choice than in-kind distribution of food or clothing, the gain in dignity is just as real. Daily life is made more ordinary, closer to "the life of a civilized being according to the standards prevailing in the society" (Marshall 1950: 11). 


\section{REFERENCES}

Alderman, Harold, et al. 2018. The 1.5 Billion People Question: Food, Vouchers, or Cash Transfer? Washington DC, USA: World Bank Group.

Buğra, Ayşe. 2015. Philanthropy and the Politics of Social Policy. in New Philanthropy and Social Justice: Debating the Conceptual and Policy Discourse, ed. B. Morvaridi, 117-136. Bristol, UK: Policy Press.

Buğra, Ayşe and Çağlar Keyder. 2003. New Poverty and the Changing Welfare Regime of Turkey. Ankara, Turkey: United Nations Development Program.

Marshall, Thomas Humphrey. 1950. Citizenship and Social Class. In Citizenship and Social Class and other Essays, ed. T.H. Marshall, 1-75. Cambridge, UK: Cambridge University Press.

Ministry of Family and Social Policy; World Bank. 2017. Turkeys's Integrated Social Assistance System. https://www.ailevecalisma.gov.tr/SYGM/PDF/ Turkeys_integrated_social_assistance_system.pdf.

Piattoni, Simona. 2001. Clientelism, Interests, and Democratic Representation: The European Experience in Historical and Comparative Perspective. Cambridge: Cambridge University Press.

Sen, Amartya. 1981. Poverty and Famines: An Essay on Entitlement and Deprivation. Oxford, UK: Oxford University Press.

White, Jenny. 2002. Islamist Mobilization in Turkey: A Study in Vernacular Politics. Seattle. USA: University of Washington Press.

World Bank. 2008. Implementation, Completion and Results Report on a Loan in the Amount of US\$500 million to the Republic of Turkey of a Social Risk Mitigation Project (Report No:ICR0000306).

Open Access This chapter is licensed under the terms of the Creative Commons Attribution 4.0 International License (http://creativecommons.org/licenses/ by $/ 4.0 /$ ), which permits use, sharing, adaptation, distribution and reproduction in any medium or format, as long as you give appropriate credit to the original author(s) and the source, provide a link to the Creative Commons licence and indicate if changes were made.

The images or other third party material in this chapter are included in the chapter's Creative Commons licence, unless indicated otherwise in a credit line to the material. If material is not included in the chapter's Creative Commons licence and your intended use is not permitted by statutory regulation or exceeds the permitted use, you will need to obtain permission directly from the copyright holder.

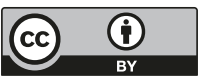

